\title{
Parental smoking, breast feeding, and respiratory infection in development of allergic diseases
}

\author{
J J COGSWELL, E B MITCHELL, AND J ALEXANDER
}

Department of Paediatrics, Poole General Hospital, Dorset, Department of Immunology, Clinical Research Centre, Northwick Park Hospital, Harrow, Middlesex, and School of Mathematics, Statistics and Computing, Thames Polytechnic, Woolwich, London

SUMMARY Environmental factors were examined as determinants of clinical disease in a five year prospective study of 73 children born to atopic parents. Clinical follow up for evidence of eczema and wheezing was combined with regular skin testing, immunoglobulin assay, and respiratory viral culture where appropriate.

Thirty six children developed eczema, which was often associated with a positive result of a skin test to ingestants in the first year and inhalants by the fifth year. Thirty two children developed one or more episodes of wheeze. Fifteen children wheezed once only, and not all of these developed atopy.

No pattern of respiratory infection in early life was characteristic of children with recurrent wheeze. There was a significant difference in parental smoking habits between children with and without episodes of wheeze at the fifth birthday. No protective effect of breast feeding could be shown.

The development of allergic disease in susceptible children is influenced by many environmental factors. Advice to families about reduction of environmental allergens continues to pose problems, but parents should be advised to avoid smoking in the child's presence.

The relation between the atopic state and the clinical expression of diseases such as bronchial asthma or atopic dermatitis remains unclear. Most young children with these disorders are atopic and exposure to allergen can, in sensitive individuals, induce bronchospasm and eczematous skin changes. Not all atopic subjects, however, develop disease. The possibility that additional influences are required for expression of disease to occur has received much attention. There have been reports on the role of diverse environmental factors in atopic subjects, including season of birth, ${ }^{1}$ respiratory infections, ${ }^{2}$ and state of breast feeding. ${ }^{3-8}$

In this five year prospective study we have followed a cohort of children $(n=97)$ at risk of allergic disease, seeking the development of eczema, recurrent wheezing, and seasonal rhinitis. We have attempted to examine how environmental factors interact on the atopic constitution and produce symptoms of disease. The incidence of early respiratory infections and the development of specific antibody to common allergens in these children has previously been reported.9 10

\section{Patients and methods}

Study design. One hundred babies were selected for study before birth on the grounds that one parent gave a history of hay fever or asthma. This selection was designed to provide a cohort of children of whom about half would be expected to develop evidence of atopy, those without atopy acting as controls. In this study atopy was defined as the presence of eczema and/or one or more positive results of a cutaneous prick test to common allergens. Written consent from pregnant mothers was obtained after full explanation that the baby would be subjected to venepunctures and the passage of a soft nasal catheter during the course of the study. All the babies were born in the maternity department of a district general hospital. The mean birth weight on leaving hospital was $3280 \mathrm{~g}$.

At one year there were 92 families on follow up. Most of the study families continued to live in the area served by the hospital, and 73 remained on follow up on the child's fifth birthday (Table 1). Parents were asked to keep a diary of their feeding 
Table 1 Reasons for the 27 withdrawals from the study

\begin{tabular}{ll}
\hline Reason & No \\
\hline Moved away & 12 \\
Lost to follow up & 10 \\
Parents decided not & 4 \\
to continue & 1 \\
\hline Other reason & 27 \\
\hline Total &
\end{tabular}

methods and smoking habits. The date of the first cow's milk feed was recorded, but this information was not available to the paediatrician (JJC) who examined the babies. The social class classification was recorded (Registrar General's Classification, 1971).

Clinical assessment. All babies were examined at birth, at 3, 6, and 12 months, and annually thereafter. At each hospital visit a clinical history was taken and added to by a daily record of respiratory symptoms and skin problems kept by the parents. Clinical examination of the skin and the respiratory tract was carried out at each visit. In addition, parents were asked to notify the hospital whenever respiratory symptoms developed; a clinical examination was then made, usually at home. A diagnosis of eczema was made when the skin of the face or flexures showed roughening, redness, or intense pruritus that persisted for four weeks or more. Transient spots or cradle cap were not regarded as eczema. The presence of eczema and wheezing was confirmed in all cases by the paediatrician (JJC) or general practitioner. Hay fever was regarded as present if nasal discharge occurred in at least two spring/summer seasons. In this report children are regarded as atopic if they developed eczema or had at least one positive result of a cutaneous prick test during the study.

Laboratory investigation. At each hospital visit immediate skin testing for hypersensitivity was carried out by prick testing with six common allergens-namely, Dermatophagoides pteronyssimus (house dust mite), mixed grass pollen, cat fur, dog dander, hen's egg, and cow's milk (Bencard Ltd). A control solution and a 1/1000 histamine solution were also used. The diameter of the wheal was recorded at 15 minutes; a positive reaction was recorded when a wheal was $3 \mathrm{~mm}$ greater than that of the negative control. All subjects showed reactivity to the histamine solution.

At each visit venepuncture was performed and the serum assayed for immunoglobulin concentrations, including total serum IgE. ${ }^{11}$
Direct viral culture was attempted whenever respiratory symptoms were notified. Nasopharyngeal secretions were taken from the symptomatic baby in the home and transported at $0^{\circ} \mathrm{C}$ to the laboratory. The methods of tissue culture have been described elsewhere. ${ }^{9}$

Saliva samples were collected from all children at 3 years. These samples were assayed for $\operatorname{IgA}$, using a double antibody radioimmune assay. ${ }^{12}$ This assay is specific for alpha determinants on $\operatorname{IgA}$, is not inhibited by secretory piece, and is not influenced by the molecular weight of the $\operatorname{IgA}$.

Statistical analysis was undertaken using analysis of variance, $t$ test, and $\chi^{2}$ test. As a result of skewness in the distribution of the IgE results, data were logarithmically transformed $(\log (1+x))$ before significance tests were performed.

\section{Results}

Clinical disease. Of the 73 children who remained on follow up for five years, 36 developed eczema. In 34

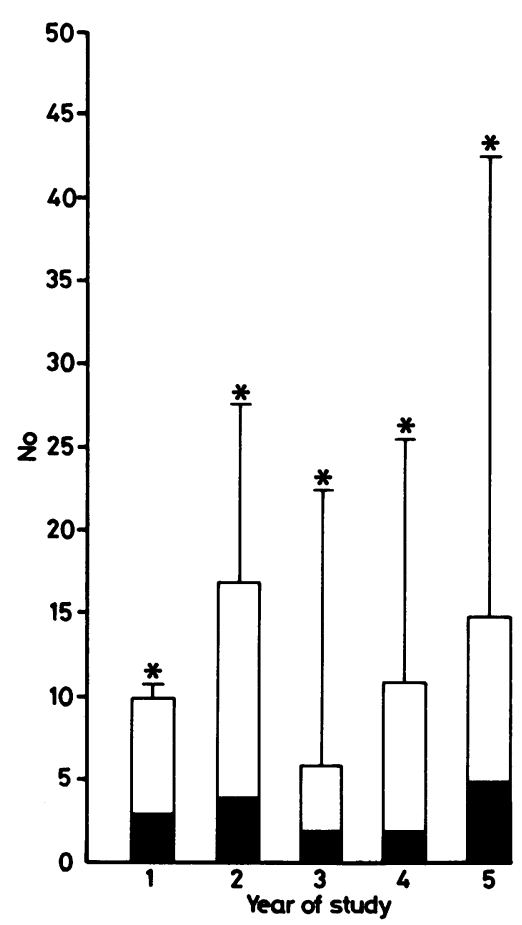

Fig. 1 Incidence of wheezing by year of study. Total bars (white + black) show number of children who experienced episodes of wheeze in each year; black bars show number of these children who had eczema in each year. Asterisk denotes total number of episodes of wheeze in each year. 
$(94 \%)$ of these the skin rash became apparent within the first two years of life. In most $(n=31)$ the skin rash persisted for less than one year and did not present an important clinical problem. In five subjects persistent skin inflammation, requiring appropriate topical treatment, was present, but even in these children there was a tendency to improve with age.

Thirty two children (44\%) had one or more episodes of wheezing. Most children $(69 \%)$ had their first episode within the first two years of life. Fifteen children had a episode of wheeze on a single occasion only. Four of the 15 children who wheezed only once showed no evidence of atopy during the five year follow up. As the remainder $(n=17)$ went on to develop recurrent attacks of wheezing the actual number of episodes of wheeze each year increased with age (Fig. 1). Eleven had four or more attacks in the five years and all of these received medical treatment, including admission to hospital in two cases. Fifteen of the 17 children with recurrent wheeze either developed eczema or had multiple positive results of cutaneous prick tests during the study.

Skin tests and clinical disease. The skin test reactiv- ity to the six common allergens is shown in Figure 2. Responses to egg and milk were most prevalent in years one and two, after which they decreased, whereas those to the major inhalant allergens house dust mite and grass pollens were more prevalent in the later years of the study. Of the 36 children with a diagnosis of eczema, 21 were atopic on the basis of results of the skin test. Eleven of these showed egg sensitivity in the first year compared with only three of the 37 children without eczema $(\mathrm{p}<0 \cdot 05)$. During the first year ingested allergens accounted for $86 \%$ of positive reactions in children with eczema (Table 2). By contrast, at year five, inhalant allergens accounted for 26 of 27 positive reactions in children with eczema.

Children with recurrent wheezing showed an increasing number of positive reactions to inhalant allergens as age increased, with 16 of 18 being classified as atopic on this basis at the end of the study. Of the 32 children who wheezed, 22 had at least one positive result of a prick test. No characteristic pattern of skin test responses occurred in children with wheeze to distinguish them from the atopic subjects who did not wheeze. Six of the eight patients with hay fever developed a positive skin reaction to mixed grass pollens within five years.
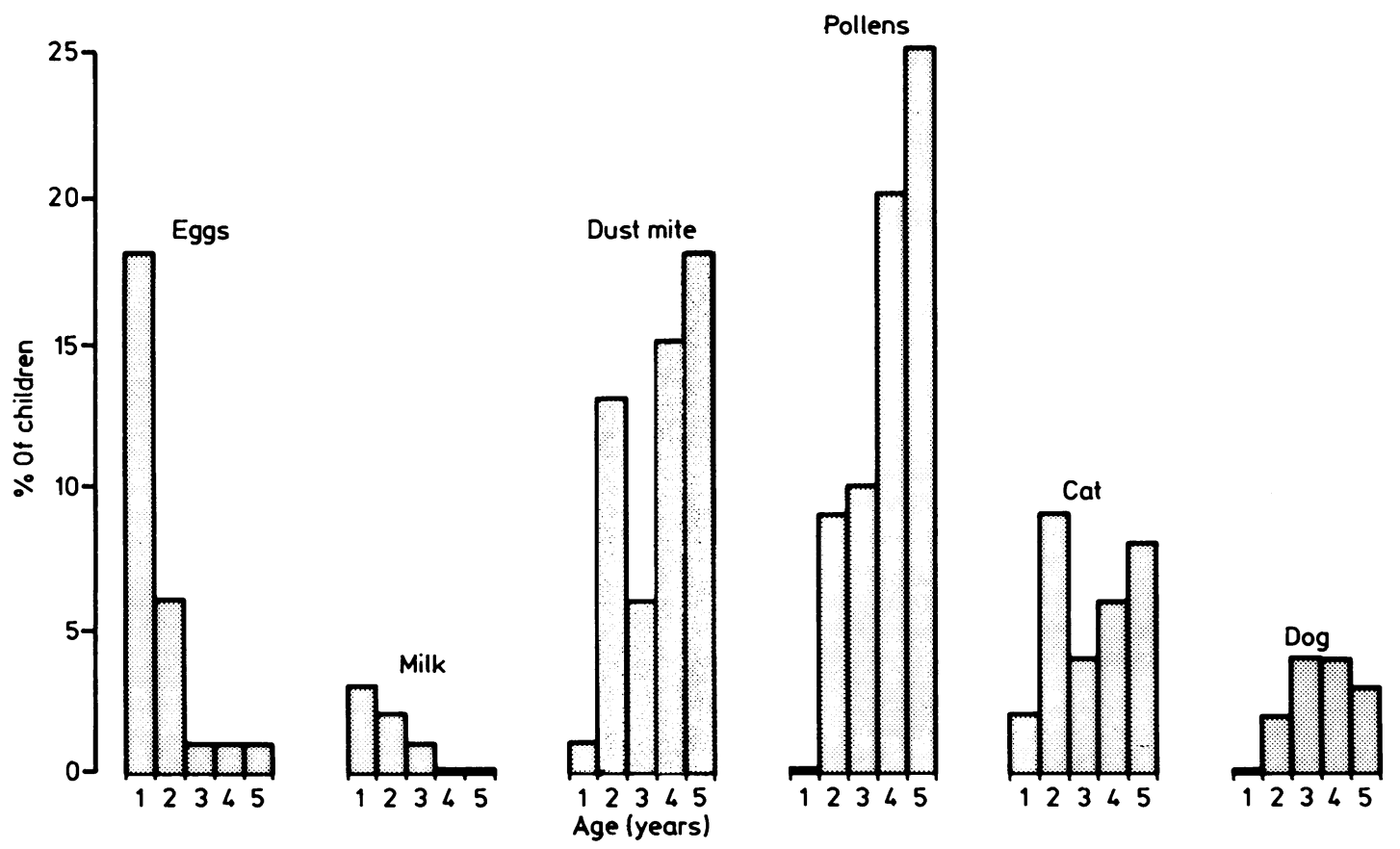

Fig. 2 Percentage of children with positive results to skin tests for the six common allergens. 
Table 2 Positive reactions to skin tests at 1,2, 3, and 5 years in 36 children who developed eczema

\begin{tabular}{lllllll}
\hline Age (years) & Antigen & & & & \\
\cline { 2 - 7 } & Egg & Dust mite & Pollens & Cat & Dog & Milk \\
\hline 1 & 6 & - & - & 1 & - & 3 \\
2 & 4 & 7 & 4 & 3 & 1 & 2 \\
3 & 1 & 4 & 11 & 3 & 2 & - \\
5 & 1 & 10 & & 2 & - & 1 \\
\hline
\end{tabular}

Immunoglobulin concentrations and clinical disease. Immunoglobulin $\mathrm{E}$ concentrations were significantly raised in both patients with eczema (Fig. 3) and those with recurrent wheezing (Fig. 4) when compared with those children who did not have these diseases at all ages after 3 months $(p<0 \cdot 05)$. Children who wheezed only once had IgE concentrations that were not significantly different from those of children who did not wheeze at all $(\mathrm{p}>0 \cdot 05)$.

No differences in serum IgA concentrations were apparent at any age between 3 and 60 months between children with and without eczema. The salivary IgA values in 3 year old subjects were not significantly different in those with and without eczema, all being within the normal adult range. ${ }^{6}$ There was no significant difference in serum $\operatorname{IgA}$ concentrations between those who did and did not have episodes of wheeze $(\mathrm{p}<0.05)$.

Parental smoking. At the children's first birthday the number of those who had developed or were to develop wheezing was equally distributed between parents who did or did not smoke at that time. By 5 years, however, $62 \%$ of parents who smoked had

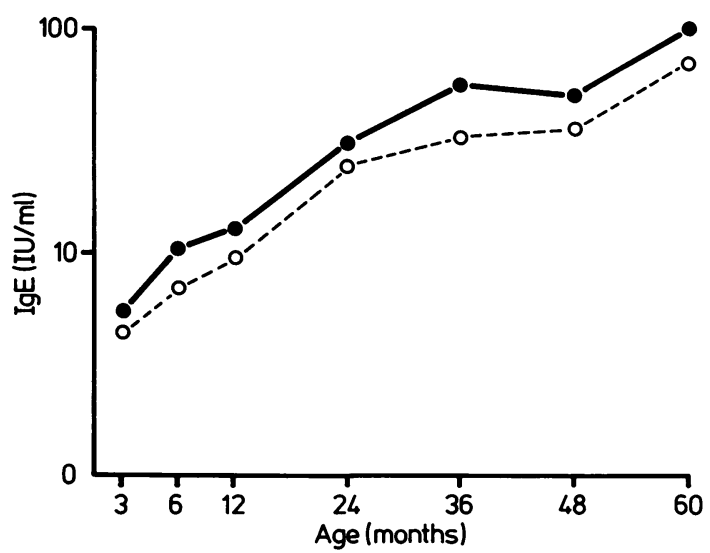

Fig. 3 IgE concentration in children according to whether they developed eczema or not. eczema $(n=36), \bigcirc--\bigcirc=$ those without eczema $(n=37)$. children who had experienced episodes of wheeze compared with $37 \%$ in families where the parents did not smoke. The difference was significant $(\mathrm{p}<\cdot 05)$ (Fig. 5).

When total serum IgE concentrations of children were compared between the families where the parents smoked and those where the parents did not smoke no significant difference could be found at any age $(p>0 \cdot 05)$.

Respiratory infections. Successful isolations of virus became less common as the children grew up, probably due to sampling difficulties. In all subjects throughout the study respiratory viruses (rhinovirus, respiratory syncytial virus, and para-influenza virus) were isolated from children with both coryzal and wheezy syndromes. The 15 children who wheezed only once often had associated coryzal symptoms. In this group five positive respiratory viral isolates were made (three respiratory syncytial virus, two para-influenza virus).

Respiratory infections occurred more often in the atopic children (mean 20.7 over five years) than in the non-atopic children (mean 15.6), but this difference did not reach significance. There was a similar

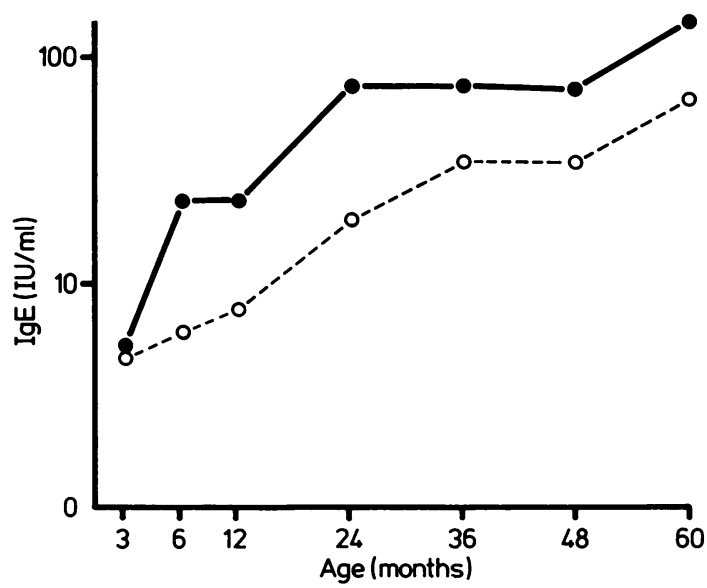

Fig. 4 IgE concentration in children according to whether they had episodes of wheeze or not. recurrent wheeze; $\mathrm{O}--\mathrm{O}=$ those without wheeze. 


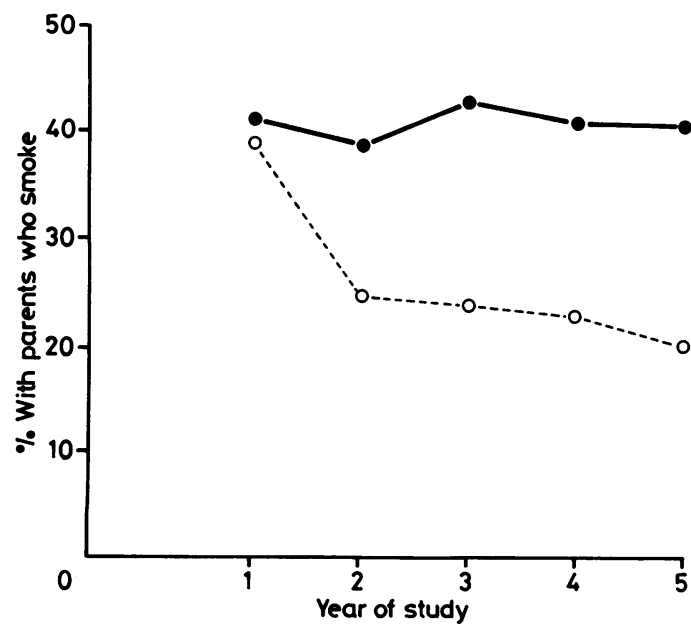

Fig. 5 Parental smoking habits and wheezing in total study population. - Children with wheeze $(n=32)$; $\mathrm{O}--\mathrm{O}=$ children without wheeze $(n=41)$.

pattern of respiratory virus infections in the atopic children during the first year of life compared with those who did not develop wheezing (Table 3).

Breast feeding. The duration of breast feeding was taken as the time from birth to the introduction of the first cow's milk or cow's milk formula feed.

In all, $55 \%$ of children received no cow's milk during the first four weeks of life and $12 \%$ were totally breast fed for over three months.

There was no evidence of any relation between the duration of breast feeding and the incidence of eczema or positive skin tests ( $p>0 \cdot 05$ ) (Table 4$)$.

No protective effect of breast feeding against asthma could be shown.

Atopic children and environmental factors. Forty eight children were identified as atopic. Twenty two developed episodes of wheeze and 26 did not. As the genetic predisposition to atopy was similar the two subgroups were compared for environmental influences.

No significant differences between the groups could be shown for social class, season of birth, or duration of breast feeding. The atopic children who had episodes of wheeze did not have significantly more respiratory infections, and the virus isolates in the first year were similar in both groups (Table 3 ).

There were significantly more parents who smoked cigarettes among the families of atopic children who had episodes of wheeze at 5 years of age than in the families of children who did not have episodes of wheeze $(p<0 \cdot 05)$ (Fig. 6).

\section{Discussion}

The prediction that roughly half of these children

Table 4 Duration of breast feeding according to atopic state

\begin{tabular}{lrrll}
\hline Atopic state & \multicolumn{4}{c}{ Duration of breast feeding (weeks) } \\
\cline { 2 - 5 } & $>4$ & $5-13$ & $14+$ & Total \\
\hline None & 14 & 10 & 1 & 25 \\
Skin test positive only & 4 & 7 & 1 & 12 \\
Eczema only & 7 & 6 & 2 & 15 \\
Skin test positive and eczema & 8 & 8 & 5 & 21 \\
\hline Total & 33 & 31 & 9 & 73
\end{tabular}

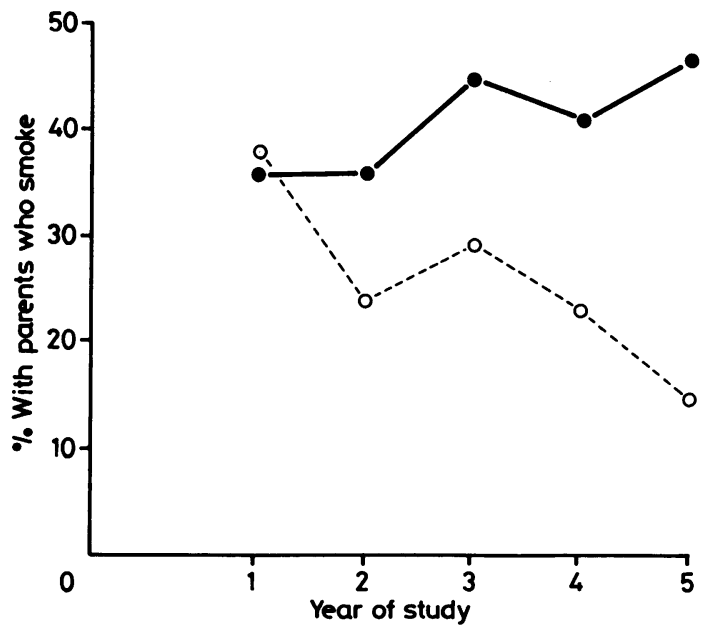

Fig. 6 Parental smoking habits and wheezing in the atopic study population. $=$ Atopic children with wheeze $(n=22) ; \bigcirc--O=$ atopic children without wheeze $(n=26)$.

Table 3 Virus isolations in 48 symptomatic children with atopy in first year of life

\begin{tabular}{|c|c|c|c|c|c|}
\hline \multicolumn{3}{|l|}{ Wheezy children } & \multicolumn{3}{|l|}{ Non-wheezy children } \\
\hline Isolates & & No & Isolates & & No \\
\hline Rhinovirus & Type H & 2 & Rhinovirus & Type $\mathbf{M}$ & 2 \\
\hline Para-influenza & 3 & 3 & Para-influenza & 3 & 3 \\
\hline Influenza & A & 1 & & & \\
\hline Respiratory syncytial virus & & 1 & Respiratory syncytial virus & & 1 \\
\hline
\end{tabular}


would develop allergic disease proved to be correct. ${ }^{13}$ The predominant clinical problem was eczema, although most of the children were affected in the first two years only. Over $40 \%$ of the children had one or more positive results to a skin test, a prevalence in agreement with a previous report on similar children. ${ }^{14}$ Most of the children with eczema were atopic, supporting an association between disease expression and the genetic predisposition to develop IgE antibody responses. The most commonly identified skin sensitivity in the first year was to egg protein. The skin reaction was often transient, disappearing in the second year at a time when the prevalence of eczema was also decreasing. These results suggest a role for food specific immune responses in the pathogenesis of infantile eczema, as has been suggested by others. Skin reactivity to inhalant allergens represented the predominant sensitivity in older children with eczema, although it developed later than that to foods. The role of inhalant allergens in the pathogenesis of eczema has received somewhat less attention. It has been shown that the raised IgE concentrations of children and adults with this disorder includes inhalant allergen specific IgE antibody. ${ }^{15}$ The presence of this antibody is not explained by concomitant respiratory allergic disease. Furthermore, the application of such allergens to the skin has been shown to induce eczematous lesions in sensitive individuals. ${ }^{16}$ Both ingested and inhaled allergens are probably of clinical importance in subjects with eczema, though their predominant effects may be at different stages of development.

In this study the children who wheezed on four or more occasions all showed evidence of atopy. The predominant sensitivity was to the major inhaled allergens. The results suggest that this preschool chest disorder is indistinguishable from asthma. Not all atopic children develop asthma, suggesting that atopy alone does not give rise to symptoms. Children who wheeze once only in the early months of life do not necessarily go on to show evidence of atopy, and their IgE concentrations are the same as those children who have no episodes of wheeze. Such episodes are usually associated with coryzal symptoms, suggesting that a single episode of wheeze can result directly from respiratory infection of this age.

As in our earlier report, ${ }^{3}$ we were again unable to confirm the observation that children with atopic symptoms had a transient deficiency of IgA concentration at 3 months. ${ }^{17}$ Differences in study design, clinical definitions, and duration of follow up may account for the conflicting results. We were unable to show that either month of birth or social class influenced the onset of asthma, but it would require much longer epidemiological studies ${ }^{18} 19$ to detect this influence.

This study confirms other observations that respiratory viruses can be isolated from young children during episodes of wheeze. ${ }^{2021}$ The same viruses were isolated, however, from children with coryzal symptoms in both atopic and non-atopic children. These findings suggest that viral infection against an atopic background does not adequately explain all symptoms. No virus, or group of viruses, could be identified as more asthmagenic than others. Due to sampling difficulties in older children, this study was unable to confirm the role of viral infections in the development of recurrent wheezing.

It is known from epidemiological studies that exposure to cigarette smoke doubles the risk to the infant of an attack of pneumonia or bronchitis. ${ }^{22}$ Our study suggests that this risk is not confined to infancy and parental smoking habits but may have an even stronger influence on the pathogenesis of wheezing in the 5 year old child. The mechanism of this effect is unclear. In adults smoking may result in an increase in bronchial hyperactivity, ${ }^{23}$ this change being only weakly dependent on the atopic state of the patient. Immunological variables can be altered in smokers, including a rise in IgE concentrations. In this study the children of parents who smoked did not show raised IgE concentrations, perhaps suggesting a different mechanism. We have reported elsewhere that the immune response to house dust mite was increased in those children exposed to higher concentrations of its major allergen, antigen p1. ${ }^{10}$ These differences include prevalence of skin test reactivity and radioallergosorbent test specific for $D$ pteronyssimus. It has been shown previously that avoidance of house dust mite both in children and young adults can result in a reduction of bronchial hyperactivity. ${ }^{24}{ }^{25}$ It is quite clear that recurrent wheezing develops in these subjects who are genetically predisposed to develop an atopic state. It is possible that cofactors, or environmental influences, such as parental smoking, house dust mite antigen, and respiratory tract infections, either by a direct effect on airway reactivity or by altering the nature of the immune response to particular allergens, are required to allow disease expression. The possibility of a synergistic effect between these factors must also be borne in mind.

Breast feeding failed to show any protective effect against the development of allergic disease, including eczema. Whether breast feeding affords protection against atopic disease remains controversial. ${ }^{3-6}$ Random controlled clinical trials have given conflicting results. As it is difficult to control how mothers feed their babies many studies have been of an observational design. Our study can be criticised 
on these grounds. Bias may have arisen if those infants most at risk opted into the breast feeding group. As the risk was equal among all babies this seems to be unlikely. Moreover, the number of breast fed babies in the trial was similar to local practice at the time. Observer bias was minimised by the clinician being unaware of the feeding history at the time of the clinical assessment. Our conclusions are similar to other recent reports. ${ }^{78}$

The finding that egg sensitivity, as shown by immediate skin test reactivity, can occur in wholly breast fed babies suggests that maternal diet may be of relevance. Food allergies in fully breast fed infants have been described. ${ }^{26}$ It has been shown in experimental rats that repeated low dose exposure through breast milk increases the likelihood of developing an IgE antibody response to a food protein. ${ }^{27}$ The increased incidence of skin tests positive to egg, in breast fed babies compared with bottle fed babies, during the past six months suggests that similar events may occur in man. While breast feeding should continue to be recommended by paediatricians as the best available feed for most babies, we do not believe that it can be promoted as a preventative measure in those infants at risk of developing allergic disease. Studies on the role of maternal exclusion dieting while breast feeding are indicated.

In conclusion, the development of asthma and eczema in susceptible children seems to be influenced by a wide variety of environmental factors. The issue of dietary exposure is as yet unresolved. Exposure to inhalant allergens such as the house dust mite can be reduced, although it is not clear what level of reduction is required to alter the natural history of the disease. ${ }^{28}$ The simplest advice that we can give the parents of atopic children is to stop smoking in the child's presence.

We are grateful to Professor T A E Platts-Mills for his encouragement and for carrying out the secretory IgA assays. Financial support for this project was received from the Medical Research Council, the Asthma Research Council, and the Wessex Regional Health Authority. We thank Mrs J Wignall for technical support and all the children and families who took part.

\section{References}

1 Morrison Smith J, Springett VH. Atopic disease and month of birth. Clin Allergy 1979;9:153-7.

2 Frick OL, Germand DF, Mills J. Development of allergy in children. Association with virus infections. J Allergy Clin Iinmunol 1979;63:228-41.

3 Burr ML. Does infant feeding affect the risk of allergy? Arch Dis Child 1983;58:561-5.

${ }^{4}$ Grulee CG, Sandford HN. The influence of breast and artificial feeding in infantile eczema. $J$ Pediatr 1936;89:223-5.

5 Johnstone DE, Dutton AM. Dietary prophylaxis of allergic disease in children. $N$ Engl $J$ Med 1966;274:715-9.

${ }^{6}$ Moore WJ, Midwinter RE, Morris AF, Colley JRT, Soothill JF.
Infant feeding and subsequent risk of atopic eczema. Arch Dis Child 1985;60:722-6.

7 Golding J, Butler NR. Taylor B. Breast feeding and eczema/ asthma. Lancet 1982; i:623.

${ }^{8}$ Gordon RR, Milford 'Ward A, Noble DA, Allen R. Immunoglobulin $\mathrm{E}$ and the eczema/asthma syndrome in early childhood. Lancet 1982;i:72-4.

${ }^{y}$ Cogswell JJ, Halliday DF, Alexander JR. Respiratory infections in the first year of life in children at risk of developing atopy. $\mathrm{Br}$ Med J 1982;284:1011-3.

${ }^{10}$ Rowntree S. Cogswell JJ, Platts-Mills TAE, Mitchell EB. Development of $\operatorname{lgE}$ and $\operatorname{IgG}$ antibodies to food and inhalant allergens in children at risk of allergic disease. Arch Dis Child 1985:60:727-35.

"Hobbs JR. Simplified radial immunodiffusion. Association of Clinical Pathologists Broadsheet, No 68. London: BMA. 1970.

12 Platts-Mills TAE. Local production of $\operatorname{IgG}, \operatorname{IgA}$ and $\operatorname{IgE}$ antibodies in grass pollen hay fever. J Immunol 1979;122: 2218-25

13 Van Arsdel PP. Matulsky AG. Frequency and hereditability of asthma and allergic rhinitis in college students. Acta Genet Statist Med 1959:9:101-14.

14 Kaufman HS, Frick OL. Immunological development in infants of allergic parents. Clin Allergy 1976;6:321-7.

15 Platts-Mills TAE, Mitchell EB, Rowntree S, Chapman MD Wilkins SR. The role of house dust mite allergens in atopic dermatitis. Clin Exp Dermatol 1983;8:233-47.

${ }^{16}$ Mitchell EB, Crow J, Chapman MD, Jouhal SS, Pope FM Platts-Mills TAE. Basophils in allergen induced patch test sites in atopic dermatitis. Lancet 1982; ;:127-30.

17 Taylor B, Norman AB. Orgel HA, Stokes CR, Turner MW. Soothill JF. Transient IgA deficiency and pathogenesis of infantile atopy. Lancet 1973;ii:111-3.

18 Taylor B, Wadsworth J, Golding J. Butler N. Breast feeding, eczema, asthma and hay fever. J Epidemiol Community Health 1983:37:95-9.

${ }^{19}$ David JJ, Beards SC. Asthma and the month of birth. Clin Allergy 1985;15:391-5.

20) Mitchell I, Inglis H, Simpson H. Viral infections in wheezy bronchitis and asthma in children. Arch Dis Child 1972:51: $707-11$.

${ }^{21}$ Horn MECM, Brain E, Gregg I, Yelland SK, Inglis JM Respiratory viral infection in childhood. A survey in general practice, Rochampton 1967-1972. J Hyg (Lond) 1975;74: $157-68$.

22 Colley JRT, Holland WW, Corkhill RT. Influence of passive smoking and parental phlegm on pneumonia and bronchitis in early childhood. Lancet 1974;ii:1031-4.

${ }^{23}$ Pride N. Smoking, allergy and airway obstruction. Clin Allergy 1986;16:3-5.

${ }^{24}$ Murray AB, Ferguson AC. Dust free bedrooms in the treatment of asthmatic children with house dust mite allergy. Pediatrics 1983;71:418-22.

25 Platts-Mills TAE, Mitchell EB, Nock P, Tovey ER, Moszoro H Wilkins SR. Reduction of bronchial hyperreactivity during prolonged allergen avoidance. Lancet 1982;ii:675-7.

26 Warner JO. Food allergy in fully breast-fed infants. Clin Allergy 1980;10:133-6.

27 Jarrett EE, Stewart DC. Rat IgE production. I. Effect of dose of antigen on primary and secondary reaginic antibody responses. Immunology 1974:27:365-81.

${ }^{28}$ Mitchell EB, Wilkins S, McCallum-Deighton J. Platts-Mills TAE. Reduction of house dust mite allergen levels in the home; use of the acaricide, pirimiphos methyl. Clin Allergy 1985;15:235-40.

Correspondence to Dr J J Cogswell, Department of Paediatrics, Poole General Hospital, Longfleet Road, Poole, Dorset BH15 2JB, England.

Received 1 December 1986 